\title{
The role of active case finding in reducing patient incurred catastrophic costs for tuberculosis in Nepal
}

Suman Chandra Gurung ${ }^{1}$, Kritika Dixit ${ }^{1}$, Bhola Rai ${ }^{1}$, Maxine Caws ${ }^{1,2}$, Puskar Raj Paudel ${ }^{3}$, Raghu Dhital', Shraddha Acharya ${ }^{1}$, Gangaram Budhathoki ${ }^{1}$, Deepak Malla', Jens W. Levy ${ }^{3}$, Job van Rest ${ }^{3}$, Knut Lönnroth ${ }^{4}$, Kerri Viney ${ }^{4,5}$, Andrew Ramsay ${ }^{6}$, Tom Wingfield ${ }^{2,7}$, Buddha Basnyat ${ }^{8}$, Anil Thapa ${ }^{9}$, Bertie Squire ${ }^{2}$, Duolao Wang ${ }^{2}$, Gokul Mishra ${ }^{1,2}$, Kashim Shah $^{10}$, Anil Shrestha ${ }^{10}$ and Noemia Teixeira de Siqueira-Filha ${ }^{2,11^{*}}$ (D)

\begin{abstract}
Background: The World Health Organization (WHO) End TB Strategy has established a milestone to reduce the number of tuberculosis (TB)- affected households facing catastrophic costs to zero by 2020. The role of active case finding (ACF) in reducing patient costs has not been determined globally. This study therefore aimed to compare costs incurred by TB patients diagnosed through ACF and passive case finding (PCF), and to determine the prevalence and intensity of patient-incurred catastrophic costs in Nepal.

Methods: The study was conducted in two districts of Nepal: Bardiya and Pyuthan (Province No. 5) between June and August 2018. One hundred patients were included in this study in a 1:1 ratio (PCF: ACF, 25 consecutive ACF and 25 consecutive PCF patients in each district). The WHO TB patient costing tool was applied to collect information from patients or a member of their family regarding indirect and direct medical and non-medical costs. Catastrophic costs were calculated based on the proportion of patients with total costs exceeding $20 \%$ of their annual household income. The intensity of catastrophic costs was calculated using the positive overshoot method. The chi-square and Wilcoxon-Mann-Whitney tests were used to compare proportions and costs. Meanwhile, the Mantel Haenszel test was performed to assess the association between catastrophic costs and type of diagnosis.

Results: Ninety-nine patients were interviewed (50 ACF and 49 PCF). Patients diagnosed through ACF incurred lower costs during the pre-treatment period (direct medical: USD 14 vs USD 32, $P=0.001$; direct non-medical: USD 3 vs USD 10, $P=0.004$; indirect, time loss: USD 4 vs USD 13, $P<0.001$ ). The cost of the pre-treatment and intensive phases combined was also lower for direct medical (USD 15 vs USD 34, $P=0.002$ ) and non-medical (USD 30 vs USD 54, $P=0.022$ ) costs among ACF patients. The prevalence of catastrophic direct costs was lower for ACF patients for all thresholds. A lower intensity of catastrophic costs was also documented for ACF patients, although the difference was not statistically significant.

Conclusions: ACF can reduce patient-incurred costs substantially, contributing to the End TB Strategy target. Other synergistic policies, such as social protection, will also need to be implemented to reduce catastrophic costs to zero among TB-affected households.
\end{abstract}

Keywords: Tuberculosis, Case finding, Cost, Catastrophic cost, Patient-incurred cost, Nepal

\footnotetext{
* Correspondence: Noemia.Teixeira.Siqueira@gmail.com

2Department of Clinical Sciences, Liverpool School of Tropical Medicine,

Liverpool, UK

${ }^{11}$ Institute for Health Technology Assessment, Porto Alegre, Brazil

Full list of author information is available at the end of the article
}

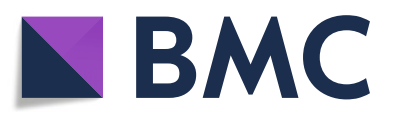

(c) The Author(s). 2019 Open Access This article is distributed under the terms of the Creative Commons Attribution 4.0 International License (http://creativecommons.org/licenses/by/4.0/), which permits unrestricted use, distribution, and reproduction in any medium, provided you give appropriate credit to the original author(s) and the source, provide a link to the Creative Commons license, and indicate if changes were made. The Creative Commons Public Domain Dedication waiver (http://creativecommons.org/publicdomain/zero/1.0/) applies to the data made available in this article, unless otherwise stated. 


\section{Multilingual abstracts}

Please see Additional file 1 for translations of the abstract into the five official working languages of the United Nations.

\section{Background}

The World Health Organization (WHO) End TB Strategy has established a goal to end the global tuberculosis (TB) epidemic. A key milestone to be achieved by 2020 is reducing the number of TB-affected households facing catastrophic costs to zero [1]. A recent systematic review including studies of sufficient quality with low risk of bias conducted in Nigeria, Peru, China, and Moldova analyzed the effect of cash interventions on treatment outcomes. The review concluded that patients receiving a TB-specific cash transfer were more likely to have a positive clinical outcome than patients in the control group (odds ratio [OR]: 1.77; 95\% confidence interval [CI]: 1.57-2.01) [2]. However, cash transfers alone are unlikely to eliminate catastrophic costs. Active case finding (ACF) has been recommended by international agencies as a supportive strategy to reduce the financial burden faced by TB patients [3, 4].

Studies have shown the importance of scaling up ACF to eliminate the gap between estimated and notified TB cases. The degree of case finding within national TB programs varies globally and therefore ACF interventions may encompass a range of strategies depending on the underlying context. These can include: household or social contact tracing, door-to-door screening, or targeted screening of high-risk groups.

In Nepal, the implementation of ACF by the Birat Nepal Medical Trust (BNMT) under the STOP TB/TB $\mathrm{REACH}$ funding programme Wave 2 (ref) was conducted in 15 Nepalese districts and detected 968 additional cases in 18 months (from January 2013 to June 2014) [5]. The ACF in Tuberculosis Trial (ACT2), which analyzed the impact of ACF using a household contact investigation of TB detection in Viet Nam, showed that the implementation of ACF, in addition to strong passive case finding (PCF), increased $\mathrm{TB}$ case detection from 703 per 100000 population in the control districts to 1788 per 100000 population in the intervention districts. Intensive household contact tracing was also found to reduce all-cause mortality in the intervention districts from $1.7 \%$ (control districts) to $0.6 \%$ (intervention districts; relative risk: 0.60 ; 95\% CI: $0.50-0.80 ; P<0.001$ ) [6]. The analysis found that household contact tracing is a highly cost-effective intervention when compared with PCF alone (USD 544 per disability-adjusted life year averted) [7].

The implementation of ACF through TB REACH has also dramatically increased the number of cases detected in Ethiopia [8] and Cambodia, in the context of extremely weak underlying national TB programs [9]. However, increases in overall notification at the national level have not been shown through these small-scale, short-term projects, thus justification for national TB programs and global funders to invest in ACF remains weak. The Zambia South Africa Tuberculosis and HIV/AIDS Reduction (ZAMSTAR) cluster randomized trial of enhanced TB case finding in the context of a high HIV prevalence failed to show an impact on culture-confirmed TB prevalence after 4 years of intervention $(O R=1.09,95 \% C I$ : 0.86-1.40) [10]. Furthermore, there is a lack of data to determine whether ACF can reduce patient-incurred costs. The WHO has been advocating strongly for research evidence from diverse settings to inform policy development to achieve the milestone of zero catastrophic costs [11].

In Nepal, the expansion of ACF is a key part of the Strategic Interventions to Increase TB Case Notification [12]. The National TB Programme (NTP) has planned to expand ACF activities through the implementation of community TB screening camps, screening of household and social contacts of index TB patients, and scaling up of GeneXpert ${ }^{\oplus}$ MTB/RIF testing (Xpert) [13]. Nepal has continued to face challenges in crucial areas, such as a sustained case detection gap, a poorly functioning health system, and high dependence on international donor funding for health (45\% of the total budget) [14, 15]. Furthermore, a significant proportion of TB patients seek care in the private sector due to weak public services [15], increasing the risk of financial hardship for the most vulnerable.

Previous cost and cost-effectiveness studies on TB conducted in Nepal have evaluated patient-incurred costs under either community-based or family member directly observed treatment strategies, short-course (DOTS) for TB control [16] and direct costs of outpatient visits to obtain a TB diagnosis $[17,18]$. This is the first study to evaluate and compare patient costs incurred through a diagnosis via ACF and PCF in the country. In a scenario of scarce financial resources, health economic evaluations play a key role in supporting the rational allocation of resources and informing evidence-based policy development. Therefore, the objective of this study was to compare costs incurred by pulmonary TB patients diagnosed through ACF and PCF, and determine the difference in prevalence and intensity of catastrophic costs between these groups.

\section{Methods}

\section{Setting}

Nepal is a low-income country with a population of 29 million people and a gross domestic product of USD 689 per capita [19]. In 2010, the poverty headcount ratio indicated that $25 \%$ of the population was living below the national poverty line [19]. In 2017, 31764 cases of TB 
were notified by the NTP. The estimated TB incidence rate was 152 cases per 100000 inhabitants, giving a case notification gap of more than 12000 cases per year [14].

This TB patient cost study was conducted in two districts of the BNMT TB REACH Wave 5 project in Nepal, which aimed to increase case notifications of TB through the implementation of ACF models (June 2017 December 2018). The BNMT TB REACH project was implemented in eight districts, with four districts applying Xpert for diagnosis (Pyuthan, Bardiya, Kapilvastu, and Gulmi) and four districts using smear microscopy (Doti, Achham, Argakhachi, and Salyan). The ACF model adopted three strategic interventions to identify TB patients: (1) contact tracing of social contacts; (2) TB camps for remote populations; and (3) screening at outpatient departments (OPDs) of public hospitals (Additional files 2 and 3). Household contacts were not evaluated in this TB REACH study because this was being carried out in the project areas as part of The Global Fund activities of the NTP.

This TB patient cost survey was conducted in two districts where the Xpert intervention was implemented: Pyuthan and Bardiya, Province No. 5 (Additional file 4). Pyuthan is a hilly district covering an area of $1309 \mathrm{~km}^{2}$ and has a population of 228102 inhabitants [20]. It is classified as a district with a medium TB burden by the NTP, with 285 cases registered in 2017 [21]. Bardiya is a lowland Terai district covering an area of $2025 \mathrm{~km}^{2}$ and has a population of 426576 inhabitants [20]. The district is classified as having a high TB burden, with 601 cases registered by the NTP in 2017 [21]. There is one government hospital in each district. In Bardiya, there are 29 health posts and three primary healthcare centers. In Pyuthan, there are 44 health posts and two primary healthcare centers. During the TB REACH project, 16 and seven TB camps were held in Bardiya and Pyuthan districts, respectively.

\section{Study design and sampling}

A cross-sectional study was conducted between June and August 2018. As no data from Nepal were available to inform a sample size determination, we set a sample size based upon a previous cost survey (TB FIT: Filipino Impact Assessment of new tuberculosis diagnostics)) [22], which was sufficient to demonstrate an effect.

One hundred patients were included in this study in a 1:1 ratio (PCF:ACF, 25 consecutive ACF and 25 consecutive PCF patients in each district). ACF patients who were between 2 weeks and 3 months into the intensive phase of TB treatment were selected from a study database of all patients diagnosed via ACF strategies. PCF patients were identified from the treatment registers at DOTS centers in each district. No eligible patients declined participation.

\section{Inclusion criteria}

All adult ( $\geq 18$ years) new and relapse TB cases registered in government facilities and who were residents of Nepal were eligible for inclusion.

\section{Case finding interventions}

Three interventions were applied in the TB REACH project. Details of the interventions are given in a paper reporting the results of the ACF intervention (forthcoming), and are described briefly below.

For the contact tracing intervention, a registered list of TB patients (index patients) diagnosed between July 2016 and July 2017 was obtained from each government treatment facility. Community Health Workers (CHWs) contacted the index patients and interviewed them to identify their social contacts. With the consent of the index patient, identified social contacts were then contacted and screened for signs and symptoms of TB using a simple symptom questionnaire (presence of cough for more than 2 weeks, blood in cough, fever, night sweats, or weight loss). Individuals reporting any of these symptoms were then invited to provide a sputum sample for testing. The CHWs collected the sputum sample in the morning and delivered the sample for testing to the nearest diagnostic facility. Those with a positive result received counseling and were referred to initiate TB treatment at the nearest health facility. Symptomatic individuals in more remote areas of the district who tested negative by smear were referred for Xpert testing at the district hospital. CHWs followed up newly diagnosed TB patients to facilitate treatment registration.

The second intervention was the establishment of TB camps in high burden or remote areas of the districts to screen, test with Xpert, and diagnose TB patients. CHWs conducted door-to-door screening using the symptom questionnaire 1 or 2 days prior to the camps being set up. Patients diagnosed with TB were enrolled into treatment by the CHWs at the nearest TB treatment center.

Symptomatic screening at the government district hospitals' OPDs was conducted among attendees using the symptom questionnaire. Symptomatic individuals were asked to provide a sputum sample for Xpert testing and those with a positive diagnosis were enrolled into treatment at the treatment center nearest to their place of residence. Rifampicin-resistant cases were referred to multi-drugresistant (MDR) TB services.

\section{Time horizon}

Costs were collected at one point in time during the intensive phase of treatment. The interviewers collected information regarding costs incurred during the pre-treatment period (that is, from the onset of the first reported TB symptom until the first visit to a health facility for initiating TB treatment) and during the intensive phase of treatment 
until the date of the interview. (that is, within 60 days of treatment initiation for new cases and 90 days for relapse cases). Costs incurred during the intensive phase were extrapolated according to the number of remaining days of treatment: costs incurred from treatment until the date of interview $\mathrm{x}$ the proportion of the intensive phase to be completed; for example, if a patient was interviewed on the 30th day (half of intensive phase completed for new cases), the cost incurred until the day of the interview was multiplied by two (proportion of intensive phase to be completed $=60 / 30)[23]$.

\section{Collecting data on costing}

The WHO TB patient costing questionnaire was adapted for this study. The questionnaire included questions on clinical parameters; demographic variables; information on employment and household composition; socioeconomic position; healthcare utilization, including the number of visits and costs (direct medical and non-medical) incurred during each visit in all types of health institutions; time and income lost (indirect costs) while seeking and receiving care; individual and family income; coping mechanisms, such as loans taken, assets sold; and the financial and social impacts of TB on patients and families.

The questionnaire was translated into Nepali and was pre-tested on seven patients undergoing TB treatment in Bardiya and Pyuthan. Minor corrections to the Nepali version of the questionnaire were made following this pilot testing. CHWs were trained in informed consent procedures and to administer the interviews. They were allocated to areas where they had relationships of trust in the community. CHWs prepared a list of TB patients diagnosed through ACF and PCF during the intervention period and contacted them to schedule an interview at their home or at the health facility. Those diagnosed via household contract tracing in The Global Fund program were not included in either group because the study's aim was to compare the TB REACH interventions with passive patient presentation. Eligible individuals were invited to participate, informed about the purpose of the study orally and by a written patient information sheet (PIS), and were given an opportunity to ask questions. The PIS was read to individuals with low literacy levels. Written informed consent was obtained, or a thumbprint for those unable to sign, following standard Nepali practice. Compensation of 500 Nepalese rupees (NPR) (approximately USD 4.5) was provided for the time taken to complete the questionnaire (approximately $90 \mathrm{~min}$ ).

Data completeness and consistency of information were assessed after each interview and were cross-checked with the patient treatment card. Data quality control was performed by the district TB coordinators, a research associate, and the data manager.

\section{Data entry and analysis}

The WHO definition was applied to estimate the proportion of TB-affected households experiencing catastrophic costs: that is, the total costs (direct plus indirect) of seeking TB diagnosis and care which exceeds $20 \%$ of the annual household income [23]. We calculated the prevalence (that is, the proportion of patients with total costs > $20 \%$ of annual household income) and the intensity of catastrophic costs (using the positive overshoot method; that is, the average degree by which catastrophic costs exceed the $20 \%$ threshold) [24] for each group. Income loss, and individual and household income were selfreported by patients. Time loss was also self-reported by patients and converted to monetary values using the human capital approach applying hourly and monthly minimum wages of USD 0.62 and USD 4.67, respectively [25]. Costs were collected in NPR and were converted to USD applying the average exchange rate from OANDA during the data collection period (NPR $1=$ USD 0.00903) (https://www1.oanda.com/) [26].

Data were entered by a trained technician into a bespoke web tool hosted by Koninklijke Nederlandse Centrale Vereniging tot bestrijding der Tuberculose (KNCV) TB Foundation and BNMT. Data analysis was performed using Stata version 15 (StataCorp, College Station, Texas 77845 , USA). The mean imputation approach was used to handle missing data and missing values were replaced by the mean value of the costing items [27]. The patients in each study arm were compared on socioeconomic and clinical characteristics. The impact of ACF on costs was determined by analyzing: (1) income changes and social consequences of TB; (2) median costs per cost component: that is, direct medical costs (drugs, tests, consultation fees, hospitalization charges), non-medical direct costs (transportation, food, accommodation), and indirect costs (time and income loss); (3) median cost per period of analysis (that is, the pre-treatment and intensive phases); and (4) proportion of direct and indirect costs per period of analysis.

The chi-square test was applied to test the difference in proportions of categorical variables. The non-parametric Wilcoxon-Mann-Whitney test was used to compare continuous variables (that is, costs). The Mantel-Haenszel analysis was performed to assess if the association between catastrophic costs and type of diagnosis (ACF vs PCF) was modified by other variables (gender, age, disease category, poverty line, dissaving, financial and social impacts). Stratified and pooled ORs and 95\% CIs were reported together with the $P$-value for the homogeneity test [28]. All $P$-values below 0.05 were considered statistically significant.

A sensitivity analysis was performed to assess the impact of varying the threshold for catastrophic costs $(10$, $20,30,40,50$, and $60 \%$ ) on the prevalence of catastrophic costs for ACF and PCF patients. The prevalence 
Table 1 Socio-economic characteristics of tuberculosis patients diagnosed through active case finding (ACF) and passive case finding (PCF), Nepal, 2018

\begin{tabular}{|c|c|c|c|c|}
\hline \multirow[t]{2}{*}{ Patient features } & $\begin{array}{l}\text { ACF } \\
N=50\end{array}$ & $\begin{array}{l}\text { PCF } \\
n=49\end{array}$ & $\begin{array}{l}\text { All } \\
n=100\end{array}$ & \multirow[t]{2}{*}{$P$-value } \\
\hline & $n(\%)$ & $n(\%)$ & $n(\%)$ & \\
\hline \multicolumn{5}{|l|}{ Sex } \\
\hline Female & $18(36)$ & $11(22)$ & $29(29)$ & \multirow[t]{2}{*}{0.139} \\
\hline Male & $32(64)$ & $38(77)$ & $70(71)$ & \\
\hline \multicolumn{5}{|l|}{ Age group } \\
\hline $15-24$ & $7(14)$ & $5(10)$ & $12(12)$ & \multirow[t]{6}{*}{0.367} \\
\hline $25-34$ & $3(6)$ & $10(20)$ & $13(13)$ & \\
\hline $35-44$ & $9(18)$ & $8(16)$ & $17(17)$ & \\
\hline $45-54$ & $10(20)$ & $8(16)$ & $18(18)$ & \\
\hline $55-64$ & $10(20)$ & $6(12)$ & $16(16)$ & \\
\hline $65+$ & $11(22)$ & $12(24)$ & $23(26)$ & \\
\hline \multicolumn{5}{|l|}{ Education status $^{\mathrm{b}}$} \\
\hline No education or illiterate & $14(28)$ & $18(36)$ & $32(32)$ & \multirow[t]{5}{*}{0.536} \\
\hline Literate & $12(24)$ & $8(16)$ & $20(20)$ & \\
\hline Basic schools & $20(40)$ & $16(32)$ & $36(36)$ & \\
\hline Secondary schools & $4(8)$ & $6(12)$ & $10(10)$ & \\
\hline Master's & - & $1(2)$ & $1(1)$ & \\
\hline \multicolumn{5}{|l|}{ Occupation } \\
\hline Farmer & $29(58)$ & $18(36)$ & $47(47)$ & \multirow[t]{3}{*}{0.229} \\
\hline Homemaker & $6(12)$ & $5(10)$ & $11(11)$ & \\
\hline Others & $15(30)$ & $26(53)$ & $41(41)$ & \\
\hline \multicolumn{5}{|l|}{ Patient as main income earner } \\
\hline Yes & $19(38)$ & $17(34)$ & $36(36)$ & 0.677 \\
\hline \multicolumn{5}{|l|}{ Source of drinking water } \\
\hline Piped & $24(48)$ & $25(50)$ & $49(49)$ & \multirow[t]{3}{*}{0.804} \\
\hline Well & $1(2)$ & $2(4)$ & $3(3)$ & \\
\hline Other & $25(50)$ & $23(46)$ & $48(48)$ & \\
\hline \multicolumn{5}{|l|}{ Toilet facilities } \\
\hline No toilets & $4(8)$ & $3(6)$ & $7(7)$ & \multirow[t]{4}{*}{0.936} \\
\hline latrine & $36(72)$ & $38(76)$ & $74(74)$ & \\
\hline Public sewage & $4(8)$ & $3(6)$ & $7(7)$ & \\
\hline Septic tank & $6(12)$ & $5(10)$ & $11(11)$ & \\
\hline \multicolumn{5}{|l|}{ Assets $^{c}$} \\
\hline Electricity & $43(86)$ & $43(86)$ & $86(86)$ & 1 \\
\hline Radio & $18(36)$ & $24(48)$ & $42(42)$ & 0.224 \\
\hline Mobile phone & $42(84)$ & $45(90)$ & $87(87)$ & 0.372 \\
\hline Table & $22(44)$ & $22(44)$ & $44(44)$ & 1 \\
\hline Chair & $23(46)$ & $25(50)$ & $48(48)$ & 0.689 \\
\hline Bed & $44(88)$ & $43(86)$ & $87(87)$ & 0.766 \\
\hline Cupboard & $14(28)$ & $17(34)$ & 31 (31) & 0.517 \\
\hline Clock & $14(28)$ & $14(28)$ & $28(28)$ & 1 \\
\hline Fan & $18(36)$ & $18(36)$ & $36(36)$ & 1 \\
\hline
\end{tabular}

Table 1 Socio-economic characteristics of tuberculosis patients diagnosed through active case finding (ACF) and passive case finding (PCF), Nepal, 2018 (Continued)

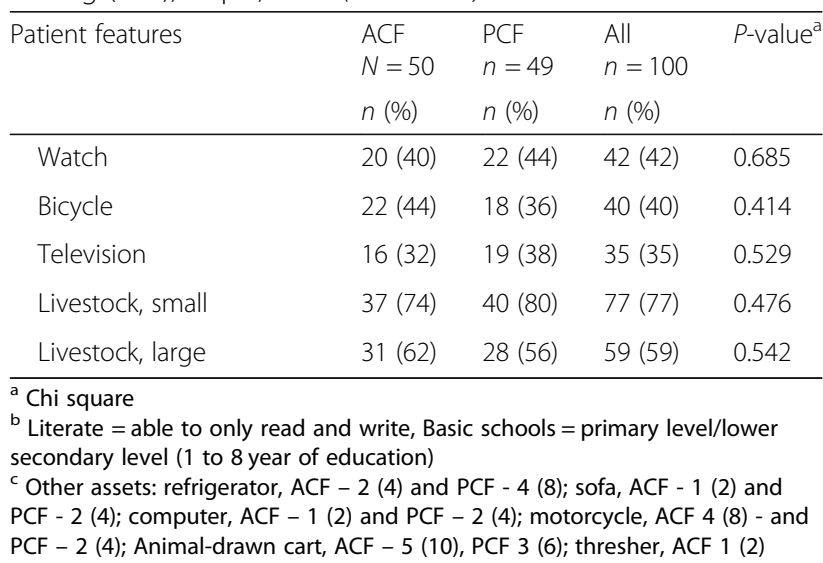

of catastrophic costs was also calculated using only the total direct costs as a proportion of the household annual income.

The effect of recall bias was also assessed in both groups. Median and interquartile costs were calculated for ACF and PCF patients interviewed within 1 month and after 1 month of treatment initiation.

\section{Results}

\section{Patient characteristics}

One hundred consecutively diagnosed TB patients were recruited. One PCF patient with extrapulmonary TB was excluded, thus the final sample was 99 patients: 50 diagnosed through ACF (three, 30, and 17 diagnosed via TB camps, OPDs, and contact tracing, respectively) and 49 diagnosed through PCF. All patients were interviewed during the intensive phase, within 14 to 90 days of treatment initiation, with $38 \%$ of patients interviewed during the first month of treatment. All eligible patients invited to participate gave written informed consent. Although MDR patients were included in the eligibility criteria, there were no MDR TB patients among those recruited. This is consistent with the MDR TB prevalence of $<1 \%$ in these districts.

No differences in the socioeconomic characteristics were found when comparing ACF and PCF patients (see Table 1 ). The majority of patients were male $(71 \%)$, consistent with the 2:1 ratio of males and females in national TB notification data. Twenty-five percent were aged over 65 years and $47 \%$ were farmers. The most common source of drinking water was piped (49\%) and the majority had a standard toilet (latrine) in the home (74\%). Electricity (86\%), a mobile phone (87\%), and a bed $(87 \%)$ were the most frequent assets reported (see Table 1).

\section{Disease and treatment characteristics}

No differences were documented in disease characteristics when comparing patients diagnosed by ACF or PCF. The 
majority of patients were classified as new TB cases (83\%) and no patient reported a HIV positive status. A similar proportion of both groups (ACF vs PCF) visited private health services during the pre-treatment period (37\% vs $41 \%)$ and sought diagnosis using public services (52\% vs $54 \%)$. The average number of visits to health facilities during the pre-treatment period ( 2.3 vs 2.6 ) and the average number of follow-up visits after treatment initiation $(0.2$ vs 0.4 ) were lower among ACF patients. However, statistical significance was reached only for follow-up visits $(P=0.026)$. The average number of weeks between the first symptom and treatment initiation was similar for ACF and PCF patients (8.4 vs $8.8, P=0.638)$ (see Table 2 ).

\section{Income changes and social consequences}

PCF patients reported a higher economic impact due to TB treatment when compared with ACF patients, with $20 \%$ of PCF patients declaring being much poorer after TB treatment initiation, while among ACF patients this proportion was $2 \%(P=0.016)$. TB resulted in a substantial decrease in the individual and household incomes of individuals diagnosed by either ACF or PCF. However, the

Table 2 Disease and treatment characteristics of tuberculosis patients diagnosed through active case finding (ACF) and passive case finding (PCF), Nepal, 2018

\begin{tabular}{|c|c|c|c|c|}
\hline Characteristics & $\begin{array}{l}\text { ACF } \\
n=50\end{array}$ & $\begin{array}{l}\text { PCF } \\
n=49\end{array}$ & $\begin{array}{l}\text { All } \\
n=100\end{array}$ & $P$-value ${ }^{a}$ \\
\hline Treatment status & $n(\%)$ & $n(\%)$ & $n(\%)$ & \\
\hline New & $42(84)$ & $40(82)$ & $82(82)$ & 0.755 \\
\hline Retreatment/Relapse & $8(16)$ & $9(18)$ & $17(17)$ & \\
\hline \multicolumn{5}{|l|}{ HIV Status ${ }^{b}$} \\
\hline Not tested & $8(16)$ & $4(8)$ & $12(12)$ & \multirow[t]{3}{*}{0.485} \\
\hline Negative & $39(78)$ & $40(83)$ & $79(79)$ & \\
\hline Unknown & $3(6)$ & $4(8)$ & $7(7)$ & \\
\hline \multicolumn{5}{|l|}{ Number of patients with reported hospitalization } \\
\hline Pre-treatment & $4(8)$ & $10(20)$ & $14(14)$ & 0.099 \\
\hline Intensive phase & 0 & $1(2)$ & $1(1)$ & - \\
\hline Total number of visits to health providers, pre-diagnosis ${ }^{c}$ & $N=114$ & $N=133$ & $N=247$ & - \\
\hline \multicolumn{5}{|l|}{ Type of service visited, pre-diagnosis } \\
\hline TB camps & $8(7)$ & 0 & $8(3)$ & \multirow[t]{5}{*}{0.031} \\
\hline Cross border service ${ }^{d}$ & 0 & $1(1)$ & $1(0.5)$ & \\
\hline Pharmacy/Herbalist & $5(4)$ & $5(4)$ & $10(4)$ & \\
\hline Private clinic/hospital & $42(37)$ & $55(41)$ & $97(39)$ & \\
\hline Public health facility & $59(52)$ & $72(54)$ & $131(53)$ & \\
\hline Total number of visits to health providers, intensive phase ${ }^{c}$ & $N=61$ & $N=64$ & $N=125$ & - \\
\hline \multicolumn{5}{|l|}{ Type of service visited, intensive phase } \\
\hline No health facility & $14(23)$ & $21(33)$ & $35(28)$ & \multirow[t]{3}{*}{0.102} \\
\hline Private clinic/hospital & $7(11)$ & $13(20)$ & $20(16)$ & \\
\hline Public health facility & $40(66)$ & $30(47)$ & $70(56)$ & \\
\hline Average number of visits to health providers & Mean (SD) & Mean (SD) & Mean (SD) & \\
\hline Health facility visits - pre-treatment & $2.3(1.1)$ & $2.6(1.6)$ & $2.5(1.4)$ & 0.380 \\
\hline Health facility visits - intensive phase & $0.9(0.9)$ & $0.9(0.9)^{c}$ & $0.9(0.9)$ & 0.500 \\
\hline Follow-up visits - Intensive phase & $0.2(0.6)$ & $0.4(1.0)$ & $0.3(0.7)$ & 0.026 \\
\hline \multicolumn{5}{|l|}{ Average number of days hospitalised } \\
\hline Pre-treatment & $5.3(3.8)$ & $8.1(7.0)$ & $7.5(6.4)$ & 0.638 \\
\hline $\begin{array}{l}\text { Average number of weeks between 1st } \\
\text { TB symptoms and treatment initiation }\end{array}$ & $8.4(8.0)$ & $8.8(11.3)$ & $8.6(9.8)$ & 0.931 \\
\hline
\end{tabular}

${ }^{a}$ Two-sample Wilcoxon rank-sum (Mann-Whitney) test and Chi square

b There is one missing data in HIV status

c Patients can have more than one visit to different health facilities

d Patient crossed the border to visit a health facility in India 
Table 3 Income changes and social consequences of tuberculosis in patients diagnosed through active case finding (ACF) and passive case finding (PCF), Nepal, 2018

\begin{tabular}{|c|c|c|c|c|}
\hline Item & $\begin{array}{l}\text { ACF } \\
n=50\end{array}$ & $\begin{array}{l}\text { PCF } \\
n=49\end{array}$ & $\begin{array}{l}\text { All } \\
n=100\end{array}$ & $P$-value ${ }^{a}$ \\
\hline Income (USD) & Mean (SD) & Mean (SD) & Mean (SD) & \\
\hline Individual income prior TB & $79(88)$ & $70(83)$ & $80(85)$ & 0.602 \\
\hline Household income prior TB & $196(111)$ & $182(184)$ & $189(151)$ & 0.052 \\
\hline Current individual income ${ }^{b}$ & $20(44)$ & $18(37)$ & $19(40)$ & 0.951 \\
\hline Current household income ${ }^{b}$ & $123(101)$ & $113(174)$ & $118(142)$ & 0.080 \\
\hline \multicolumn{5}{|l|}{ Working hours per week } \\
\hline Prior TB & $31(28)$ & $29(29)$ & $30(29)$ & 0.584 \\
\hline Current $^{\mathrm{b}}$ & $5(11)$ & $4(11)$ & $4(11)$ & 0.643 \\
\hline \multicolumn{5}{|l|}{ Catastrophic costs } \\
\hline \multirow[t]{2}{*}{ Intensity ${ }^{c}$} & $61(53)$ & $88(172)$ & $76(132)$ & 0.6713 \\
\hline & N (\%) & $N(\%)$ & $N(\%)$ & \\
\hline Prevalence $^{d}$ & $20(45)$ & $24(61)$ & $44(53)$ & 0.143 \\
\hline \multicolumn{5}{|l|}{ Employment status prior TB } \\
\hline Unemployed & $2(4)$ & $5(10)$ & $7(7)$ & 0.475 \\
\hline Formal paid work & $4(8)$ & $7(14)$ & $11(11)$ & \\
\hline Informal paid work & $24(48)$ & $17(34)$ & $41(41)$ & \\
\hline Housework & $15(30)$ & $13(26)$ & $28(28)$ & \\
\hline Others & $5(10)$ & $8(16)$ & $13(13)$ & \\
\hline \multicolumn{5}{|l|}{ Current employment status ${ }^{\mathrm{b}}$} \\
\hline Unemployed & $13(26)$ & $18(36)$ & $31(31)$ & 0.310 \\
\hline Formal paid work & - & $2(4)$ & $2(2)$ & \\
\hline Informal paid work & $5(10)$ & $2(4)$ & $7(7)$ & \\
\hline Housework & $29(58)$ & $23(46)$ & $52(52)$ & \\
\hline Others & $3(6)$ & $5(10)$ & $8(8)$ & \\
\hline \multicolumn{5}{|l|}{ Poverty headcount ${ }^{\mathrm{e}}$} \\
\hline Before TB & $5(10)$ & $6(12)$ & $11(11)$ & 0.749 \\
\hline Current $^{\mathrm{b}}$ & $13(26)$ & $16(32)$ & $29(29)$ & 0.509 \\
\hline \multicolumn{5}{|l|}{ Dissaving strategies ${ }^{b}$} \\
\hline Loan & $14(28)$ & $22(44)$ & $36(36)$ & 0.096 \\
\hline Sale of assets & $4(8)$ & $5(10)$ & $9(9)$ & 0.727 \\
\hline \multicolumn{5}{|l|}{ Social impact ${ }^{b}$} \\
\hline Food insecurity & $13(26)$ & $13(26)$ & $26(26)$ & 1 \\
\hline Loss job & $2(4)$ & $4(8)$ & $6(6)$ & 0.400 \\
\hline Interrupted schooling & $4(8)$ & $2(4)$ & $6(6)$ & 0.400 \\
\hline Social exclusion & $10(20)$ & $7(14)$ & $17(17)$ & 0.424 \\
\hline Others & $4(8)$ & $1(2)$ & $5(5)$ & 0.169 \\
\hline
\end{tabular}


Table 3 Income changes and social consequences of tuberculosis in patients diagnosed through active case finding (ACF) and passive case finding (PCF), Nepal, 2018 (Continued)

\begin{tabular}{llll}
\hline Item & ACF \\
$n=50$ & PCF & $n=49$ & $\begin{array}{l}\text { All } \\
n=100\end{array}$ \\
\hline Financial impact & & & \\
Much poorer & $1(2)$ & $10(20)$ & $11(11)$ \\
Poorer & $26(52)$ & $22(44)$ & $48(48)$ \\
Unchanged & $23(46)$ & $18(36)$ & $41(41)$ \\
\hline
\end{tabular}

${ }^{\text {a }}$ Chi square

b Intensive phase

c Intensity of catastrophic costs measured as median-positive overshoot beyond the $20 \%$ threshold

d Percentage of patients with total costs $>20 \%$ of annual family income (WHO)

e Number of families living with an annual income per capita below NPR 12000 (2011 prices) (http://www.thepovertyline.net/nepal

higher impoverishment rate among PCF patients did not appear to be a consequence of income reduction: there was no difference in the income reduction between the diagnostic groups, but rather time loss and out-of-pocket expenses (further details below). The individual income reduced by 75 and $74 \%$ for ACF and PCF patients, respectively. The reduction in the household income was 37 and 38\% for ACF and PCF patients, respectively. The poverty headcount during the intensive treatment phase also increased substantially in both diagnostic groups: 160 and $167 \%$ for individuals diagnosed by ACF or PCF, respectively. A quarter of all patients (26\%) reported food insecurity as a consequence of TB (see Table 3).

\section{Costs}

For the pre-treatment period, ACF patients reported lower direct medical (USD 14 vs USD 32; $P=0.001$ ), non-medical (USD 3 vs USD 10; $P=0.004$ ), and indirect (USD 4 vs USD 13; $P<0.001$ ) costs, the latter measured using the human capital approach (that is, based on time loss). The median total costs in this phase were also lower for ACF patients, although not statistically significant (USD 132 vs USD 172, $P=0.103$ ) (see Table 4).

During the intensive treatment phase, ACF patients also incurred lower direct non-medical (USD 0 vs USD 1), indirect (USD 55 vs USD 60), and total (USD 85 vs USD 104) costs. However, statistical significance was found only for direct non-medical costs $(P=0.034)$.

The median total cost (pre-treatment plus intensive phase) was also lower for ACF patients, particularly for direct medical (USD 15 vs USD $34, P=0.002$ ) and nonmedical (USD 30 vs USD 54, $P=0.022$ ) costs. The total direct costs were $65 \%$ lower for ACF patients compared with PCF patients (USD 40 vs USD 115, $P=0.001$ ) (see Table 4).

Indirect costs, particularly income loss, were the main driver of the total costs for both groups during the pretreatment and intensive phases. However, PCF patients had higher percentages of direct medical (34\% vs $10 \%$ ) and non-medical ( $9 \%$ vs $5 \%, P<0.001)$ costs during the pre-treatment period (see Fig. 1).

\section{Catastrophic costs}

Eighty-four patients were included in this analysis as 15 patients were unable to report the value of household income. ACF patients presented 26\% lower prevalence ( $45 \%$ vs $61 \%$ ) and $69 \%$ lower intensity (53\% vs $172 \%$ ) of catastrophic costs, considering direct and indirect costs (see Table 3).

Stratified analysis (Mantel-Haenszel) used to investigate variables influencing the association of diagnostic strategy with risk of catastrophic costs showed that stratification by gender, TB relapse, poverty level, dissaving, and financial and social impacts did not change the $O R$ of incurring catastrophic costs. However, stratification by age revealed significant heterogeneity in the odds of incurring catastrophic costs $(P=0.043)$, with those aged under 60 years having an OR of 4.6 (95\% CI: 1.1919.32) for catastrophic costs when diagnosed passively rather than actively, compared to an OR of 0.6 (95\% CI: $0.93-3.61$ ) in those aged over 60 years (see Table 5).

\section{Sensitivity analysis}

The prevalence of catastrophic costs was higher for PCF patients in all thresholds analyzed. Using the WHO threshold (that is, $20 \%$ of annual household income) and only direct costs, the prevalence of catastrophic costs was $61 \%$ lower for ACF patients when compared with PCF patients (13\% vs $33 \%, P=0.029)$ (see Fig. 2).

PCF patients were more strongly affected by recall bias and lower costs were reported for patients interviewed after 1 month of treatment initiation when compared with those interviewed within 1 month of treatment initiation. This suggests that in fact the PCF costs are more likely to be underestimated and the effect of ACF on reducing patient incurred costs is in fact greater than estimated from these self-reported data. PCF patients interviewed after 1 month of treatment reported lower indirect (USD 29 vs USD 282, $P<0.001$ ) and total (USD 128 vs USD 366, $P=$ 0.007 ) costs during the pre-treatment period, than PCF patients patient interviewed greater than 30 days after treatment initiation;. This difference was also seen for lower direct non-medical (USD 16 vs USD 81, $P=0.005$ ) and 
Table 4 Median pre-treatment and treatment costs in tuberculosis patients diagnosed through active case finding (ACF) and passive case finding (PCF), Nepal, 2018

\begin{tabular}{|c|c|c|c|c|}
\hline Cost item & $\begin{array}{l}\text { ACF } \\
(n=50)\end{array}$ & $\begin{array}{l}\text { PCF } \\
(n=49)\end{array}$ & $\begin{array}{l}\text { Total } \\
(n=100)\end{array}$ & $P$-value \\
\hline Pre-treatment period & Median (IQR) & Median (IQR) & Median (IQR) & \\
\hline \multicolumn{5}{|l|}{ Direct medical } \\
\hline Consultation fee & $0.0(0.0-0.1)$ & $0.2(0.0-4.5)$ & $0.0(0.0-1.0)$ & 0.003 \\
\hline Radiography & $0.5(0.0-3.2)$ & $3.2(0.0-9.9)$ & $1.6(0.0-5.6)$ & 0.003 \\
\hline Lab tests & $1.1(0.0-3.4)$ & $2.7(0.0-5.7)$ & $1.8(0.0-4.1)$ & 0.092 \\
\hline Medicines & $5.9(0.0-16.8)$ & $18.3(1.5-36.7)$ & $8.1(0.5-25.6)$ & 0.021 \\
\hline Other medical & $0.0(1.8-4.5)$ & $3.3(1.4-6.6)$ & $2.7(0.0-5.8)$ & 0.013 \\
\hline Total direct medical & $14.3(4.5-27.7)$ & $31.6(11.0-79.1)$ & $19.2(6.3-46.3)$ & 0.001 \\
\hline \multicolumn{5}{|l|}{ Direct non-medical } \\
\hline Transportation & $3.3(0.9-7.2)$ & $5.4(1.8-15.5)$ & $3.7(1.8-10.4)$ & 0.031 \\
\hline Food & - & $0.0(0.0-10.8)$ & $0.0(0.0-2.7)$ & 0.006 \\
\hline Total direct non-medical & $3.4(1.8-10.4)$ & $9.7(2.7-37.9)$ & $5.4(2.1-22.4)$ & 0.004 \\
\hline \multicolumn{5}{|l|}{ Indirect } \\
\hline Time loss ${ }^{a}$ & $4.4(1.9-8.1)$ & $13.4(5.6-21.8)$ & $7.8(3.7-15.0)$ & $<0.001$ \\
\hline Income loss & $51.4(0.0-240.1)$ & $30.7(0.0-201.8)$ & $40.6(0.0-212.9)$ & 0.629 \\
\hline Total indirect & $63.5(5.0-255.1)$ & $43.3(14.3-248.2)$ & $51.1(8.4-251.6)$ & 0.430 \\
\hline Total cost pre-treatment & $132.3(22.6-258.0)$ & $172.3(59.9-405.4)$ & $147.3(41.6-304.9)$ & 0.103 \\
\hline \multicolumn{5}{|l|}{ Intensive phase } \\
\hline \multicolumn{5}{|l|}{ Direct medical } \\
\hline Consultation fee/charges & - & - & - & - \\
\hline Radiography/lab tests & - & - & - & - \\
\hline Medicines & - & $0.0(0.0-1.8)$ & - & 0.045 \\
\hline Total direct medical & - & $0.0(0.0-4.0)$ & - & 0.070 \\
\hline \multicolumn{5}{|l|}{ Direct non-medical } \\
\hline Transportation & $0.0(0.0-7.2)$ & $0.4(0.0-17.3)$ & $0.0(0.0-8.5)$ & 0.041 \\
\hline Food & $0.0(0.0-6.8)$ & $0.0(0.0-19.5)$ & $0.0(0.0-7.7)$ & 0.547 \\
\hline Total direct non-medical & $0.0(0.0-14.4)$ & $1.3(0.0-44.8)$ & $0.0(0.0-28.0)$ & 0.034 \\
\hline \multicolumn{5}{|l|}{ Indirect } \\
\hline Time loss ${ }^{a}$ & $29.9(15.0-44.9)$ & $31.0(11.7-59.8)$ & $29.9(15.0-56.1)$ & 0.816 \\
\hline Income loss & $18.1(0.0-49.7)$ & $9.6(0.0-45.2)$ & $17.1(0.0-45.2)$ & 0.377 \\
\hline Total indirect & $54.9(29.9-95.9)$ & $59.6(34.9-82.7)$ & $55.1(29.9-90.5)$ & 0.817 \\
\hline \multicolumn{5}{|l|}{ Other } \\
\hline Nutritional supplements & $13.6(7.5-25.4)$ & $15.5(9.3-35.3)$ & $14.9(8.1-27.8)$ & 0.404 \\
\hline Total costs intensive phase & $84.7(56.1-144.0)$ & $103.7(45.3-193.2)$ & $96.6(51.8-176.9)$ & 0.557 \\
\hline \multicolumn{5}{|c|}{ Total cost pre-treatment and intensive phase } \\
\hline Total direct medical costs & $14.9(4.5-46.1)$ & $34.1(13.1-87.5)$ & $22.6(6.7-63.8)$ & 0.002 \\
\hline Total direct non-medical costs & $29.6(15.6-55.1)$ & $54.0(21.5-124.6)$ & $37.5(17.8-83.5)$ & 0.022 \\
\hline Total direct costs & $40.2(26.1-91.7)$ & $114.9(45.3-250.5)$ & $68.5(31.7-148.6)$ & 0.001 \\
\hline Total indirect costs & $128.2(34.9-357.4)$ & $106.1(57.8-340.9)$ & $112.4(52.4-343.7)$ & 0.942 \\
\hline Total $^{c}$ & $252.8(80.9-452.8)$ & $315.3(125.8-543.9)$ & $290.1(88.7-476.7)$ & 0.161 \\
\hline
\end{tabular}

${ }^{a}$ Hourly minimum wage: USD 0.62; Daily minimum wage: USD 4.67 (http://www.pioneerlaw.com/news/minimum-wage-remuneration-2018-2075)

${ }^{b}$ Wilcoxon-Mann-Whitney

c Total cost: from the 1st TB symptoms until the end of intensive phase 


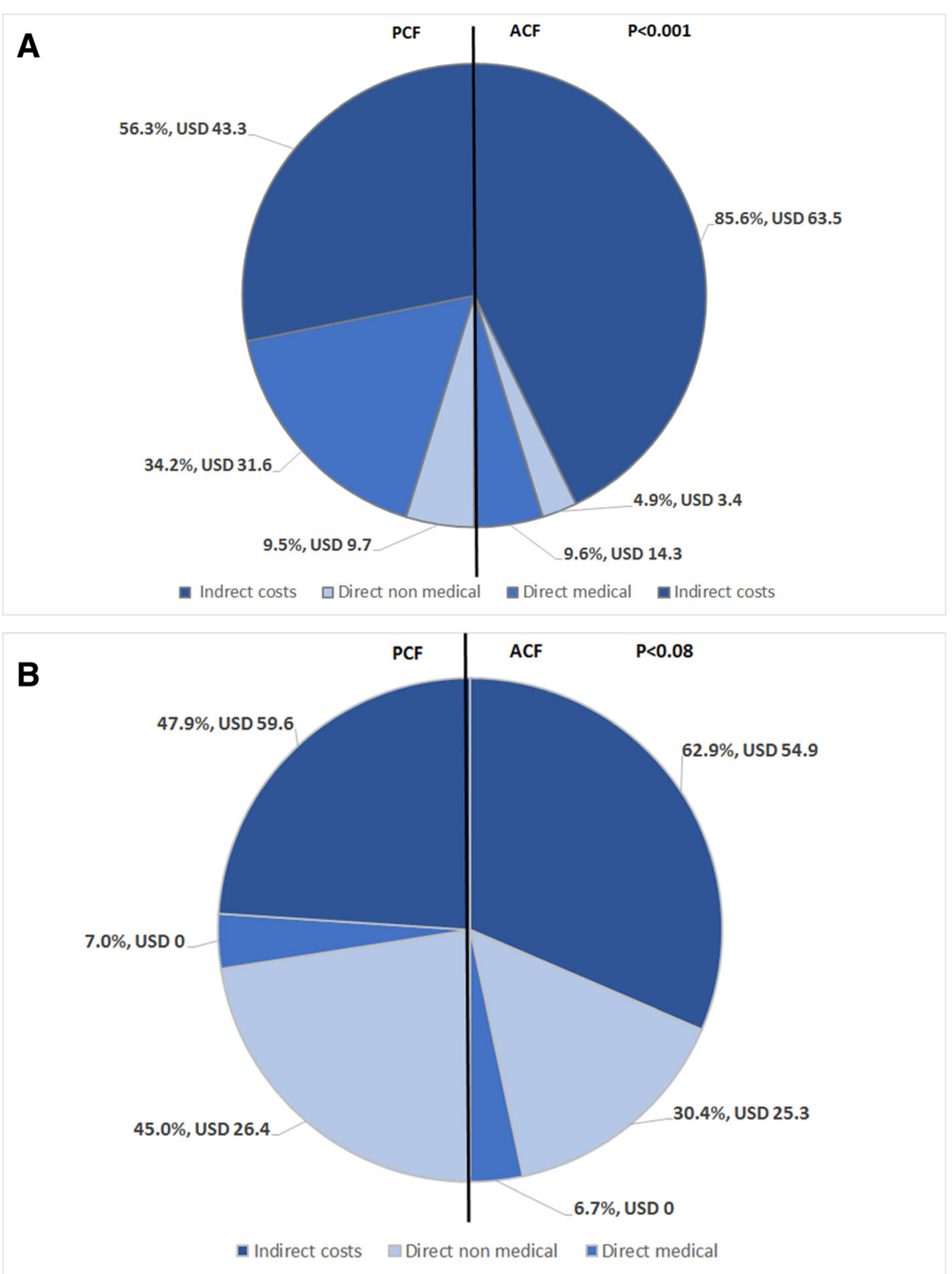

Fig. 1 The proportion of total costs attributed to each cost category (indirect, direct medical and direct non-medical) for patients diagnosed by either ACF (right side of pie chart) or PCF (left side of pie chart). The median cost incurred for each category is also shown in USD. Legend: $P$-value: Pearson's chi-square test

total (USD 68 vs USD 190, $P=0.004$ ) costs during the intensive phase; and lower indirect (USD 76 vs USD 367, $P=0.003$ ) and total (USD 232 vs USD 556, $P=0.002$ ) costs during both periods combined. There was no difference in costs among ACF patients interviewed within and after 1 month of treatment initiation (see Table 6).

\section{Discussion}

This study demonstrated that patients diagnosed through ACF incurred substantially lower costs than those diagnosed by PCF, with $65 \%$ lower direct costs and $61 \%$ lower catastrophic cost prevalence when considering only direct costs. The study also confirms the devastating financial impact of TB on poor households in Nepal and the high prevalence of catastrophic costs incurred by TB-affected households in both groups, but particularly among patients diagnosed by PCF who are aged under 60 years.

Other costing surveys conducted in Asia have also found lower costs and catastrophic costs among patients diagnosed through ACF when compared with PCF. In Cambodia, ACF patients incurred 79\% lower total costs during the pre-treatment period (USD 5 vs USD $24, P<$ 
Table 5 Association between catastrophic costs and passive case finding (PCF)/ active case finding (ACF) adjusted for each exposure variable at time, Nepal, 2018

\begin{tabular}{|c|c|c|c|c|c|}
\hline \multirow[t]{2}{*}{ Variable } & \multicolumn{2}{|c|}{ Cases of catastrophic costs per diagnostic method $n / N(\%)^{a}$} & \multicolumn{2}{|c|}{$O R^{\mathrm{b}}$ (95\% confidence interval) } & \multirow[t]{2}{*}{$P$-value ${ }^{c}$} \\
\hline & $\begin{array}{l}\text { PCF } \\
N=45\end{array}$ & $\begin{array}{l}\text { ACF } \\
N=39\end{array}$ & Stratified & Pooled & \\
\hline Total population & $24 / 39(61)$ & $20 / 45(44)$ & $2(0.77-5.25)$ & & \\
\hline \multicolumn{6}{|l|}{ Variables } \\
\hline \multicolumn{6}{|l|}{ Gender } \\
\hline Male & 20/31 (65) & $14 / 28(50)$ & $1.8(0.56-5.89)$ & $1.8(0.75-4.44)$ & 0.993 \\
\hline Female & $4 / 8(50)$ & $6 / 17(35)$ & $1.8(0.24-13.84)$ & & \\
\hline \multicolumn{6}{|l|}{ Age } \\
\hline$<60$ & $20 / 25(80)$ & $14 / 30(47)$ & $4.6(1.19-19.32)$ & $2.1(0.86-5.17)$ & 0.043 \\
\hline$\geq 60$ & 4/14 (29) & $6 / 15(40)$ & $0.6(0.93-3.61)$ & & \\
\hline \multicolumn{6}{|l|}{ Disease category } \\
\hline New case & 19/33 (58) & $17 / 38(45)$ & $1.7(0.59-4.78)$ & $2.0(0.83-4.78)$ & 0.330 \\
\hline Relapse & 5/6 (83) & 3/7 (43) & $6.7(0.34-392.48)$ & & \\
\hline \multicolumn{6}{|l|}{ Poverty line } \\
\hline Bellow & $4 / 5(80)$ & $5 / 8(62)$ & $2.4(0.11-156.99)$ & $2.1(0.87-5.19)$ & 0.924 \\
\hline Above & 20/34 (58) & $15 / 37(40)$ & $2.1(0.73-6.03)$ & & \\
\hline \multicolumn{6}{|l|}{ Dissaving } \\
\hline Yes & 13/18 (72) & $9 / 15(60)$ & $1.7(0.32-9.60)$ & $1.8(0.75-4.49)$ & 0.922 \\
\hline No & $11 / 21(52)$ & $11 / 30(37)$ & $1.9(0.53-6.84)$ & & \\
\hline \multicolumn{6}{|l|}{ Financial impact } \\
\hline Poorer /Much poorer & 15/22 (68) & $14 / 26(54)$ & $1.8(0.48-7.15)$ & $2.1(0.85-5.06)$ & 0.758 \\
\hline Unchanged & 9/17 (53) & $6 / 19(31)$ & $2.4(0.52-11.78)$ & & \\
\hline \multicolumn{6}{|l|}{ Social impact ${ }^{d}$} \\
\hline Yes & 10/14 (71) & 14/23 (61) & $1.6(0.32-9.13)$ & $2.5(0.98-6.23)$ & 0.437 \\
\hline No & $14 / 25(56)$ & $6 / 22(27)$ & $3.4(0.86-14.08)$ & & \\
\hline
\end{tabular}

a Five ACF and 11 PCF patients with "zero" annual family income excluded from this analysis

${ }^{\mathrm{b}}$ Odds ratio $(O R)$ was calculated using Mantel-Haenszel method

c $P$-value is from homogeneity test in Mantel-Haenszel analysis

d Social impact: divorce or social exclusion or food insecurity or loss of job or Interrupted schooling

0.001, costs inflated to 2018 prices) [29]. In India, a TB patient cost survey conducted in vulnerable populations found 75\% lower total costs (USD 5 vs USD 20, $P<$ 0.001, 2018 prices) and 32\% lower catastrophic costs (adjusted prevalence ratio: 0.68, 95\% CI: [0.69-0.97]) for ACF patients [30].

The findings of this study indicate that ACF has the potential to avert a substantial portion of direct costs and catastrophic direct costs associated with TB diagnosis and care, and can thereby help reduce the broader socioeconomic consequences of TB in Nepal. Previous TB patient cost surveys conducted among PCF patients in the country have found that high direct costs (that is, transportation, clinical fees, and tests) pose a barrier for patients seeking TB diagnosis and treatment $[17,18]$. In addition, high costs have been associated with adverse TB outcomes such as a delay in seeking diagnosis and starting treatment [31, 32], death, and treatment abandonment or treatment failure [33]. Thus, the implementation of ACF can potentially contribute to improved treatment outcomes and reduce mortality [7]. These outcomes will be analyzed in an ongoing project in Nepal (IMPACT TB).

The impact of ACF on direct costs, particularly during the pre-treatment period, is principally a consequence of savings incurred in transportation and diagnostic tests. Nepal has a poor transport infrastructure, and many patients live in areas without roads and therefore have to travel several hours or even several days to reach a health service. ACF reduces or removes the need for patients to travel long distances to reach diagnostic centers, or make use of private health services, and pay for laboratory tests or radiography. ACF patients receive visits from healthcare workers for TB screening, sputum collection, and further referral for $\mathrm{TB}$ treatment for those with a positive diagnosis. Besides decreasing patient costs, ACF increases accessibility to health care. 


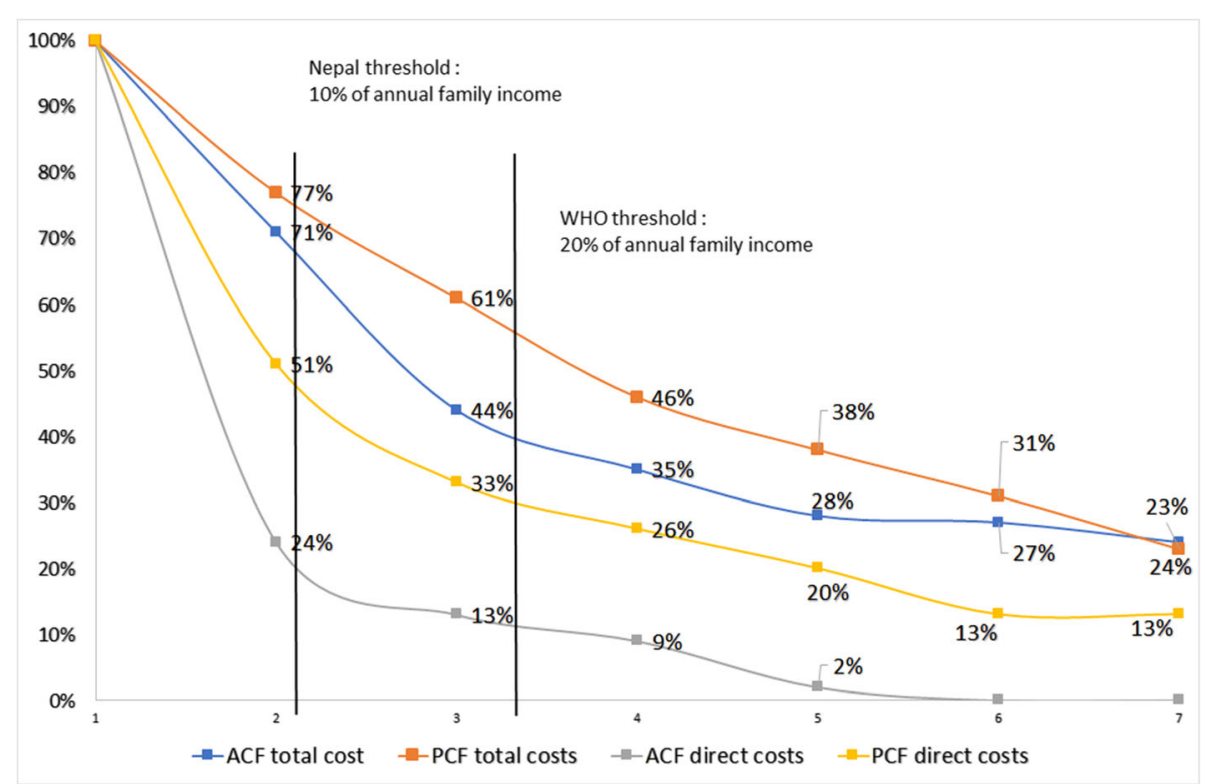

Fig. 2 Prevalence of catastrophic costs in tuberculosis patients diagnosed through active case finding (ACF) and passive case finding (PCF) during the pre-treatment and intensive phases, Nepal, 2018

Other community-based initiatives covering different areas of public health have been successful in improving access to health care. China's barefoot doctor system (1968-1985) expanded the coverage of healthcare services, reduced costs, and provided timely treatment by training indigenous paramedics in rural areas of China [34]. In Nepal, female CHVs have also improved access to health care in urban and rural areas by delivering health promotion and prevention activities at the household level [35]. Furthermore, village health workers, who were focused on immunization programs, were promoted to auxiliary health workers by the Ministry of Health in 2014-2015. The new role was expanded to provide preventive and promotive health services and basic curative services for the community $[35,36]$.

A difference in total income loss was not identified in this study, probably because the ACF strategy did not appear to provide an earlier TB diagnosis. Earlier diagnosis among patients diagnosed through ACF was identified in previous studies in Cambodia [37] and Viet Nam [6], however, both studies evaluated ACF among household contacts of index patients in addition to social contacts.

This study has a number of limitations. First, the calculation of catastrophic costs considered self-reported household income. This approach does not consider dissaving strategies and it is more challenging to apply in countries with strong informal economies and seasonal fluctuations in income, such as Nepal. However, the interviewers were advised to ask about and explore the average annual monthly income, regardless of seasonality of the market. In addition, this approach has been widely used [29, 30, 33, 38], which allows for comparisons to be made between our findings and other studies. Second, the calculation of catastrophic costs did not include costs incurred during the continuation phase of treatment, thus its prevalence was underestimated. Third, the analysis did not detect an association between key variables, such as poverty line, social and financial impacts, dissaving strategies, and the occurrence of catastrophic costs. A larger sample size may be required to identify these associations. Fourth, patients were recruited at different time points during the intensive phase, which influenced the degree of recall bias [39]. In this study, PCF patients were more affected by recall bias than ACF patients, and may have underestimated their indirect, non-medical, and total costs as they were interviewed 1 month after treatment initiation. Thus, as these patients underestimated costs, the difference in costs between ACF and PCF patients may be even higher.

The study also has a number of strengths. Interviews were conducted by trained health workers who had a previous relationship with the community. The adoption of this strategy was crucial to collect complete and accurate data because a relationship of trust between interviewer and participant is essential when asking sensitive questions about personal or household income. The present study provides important evidence to inform policy evolution for ACF scale-up in Nepal. Knowledge of the components, drivers, and distribution of costs for TB-affected households will be necessary to develop and advocate for effective interventions to mitigate costs and achieve the End TB Strategy's goal to reduce the number of TBaffected households facing catastrophic costs to zero. Our 


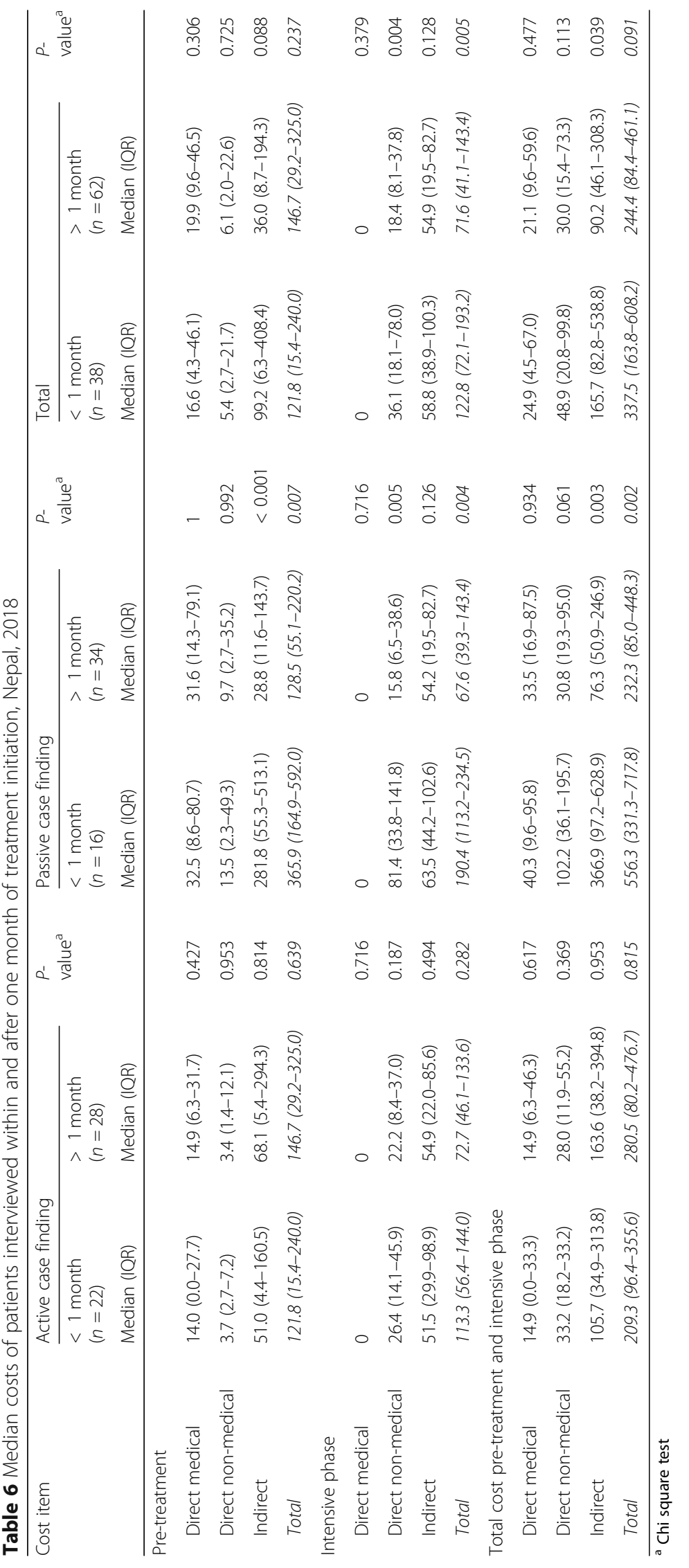


findings indicate that $\mathrm{ACF}$ is an important strategy to contribute to the achievement of this goal. A national TB patient cost survey for Nepal would provide comprehensive data and should be prioritized. The impact of ACF on catastrophic costs in other countries and population groups should also be robustly evaluated to inform global policy. Even though ACF reduced costs, the prevalence of catastrophic costs was still found to be very high in both groups. The expansion in coverage of social protection would play an important role in alleviating extreme poverty and, indirectly, in reducing TB incidence [40]. Cash transfer programs, such as Bolsa Família in Brazil, have been successful in reducing poverty and improving $\mathrm{TB}$ treatment outcomes [41]. In Peru, socioeconomic support for TB patients has improved TB outcomes and prevented catastrophic costs $[33,42]$. Similar interventions should be piloted, evaluated, and integrated into the NTP in Nepal.

\section{Conclusions}

ACF is an important strategy to avert direct costs and to reduce the proportion of TB households incurring catastrophic direct costs. Other policies, such as social protection, should be implemented in combination with $\mathrm{ACF}$ to mitigate the financial burden of $\mathrm{TB}$, particularly among the most vulnerable populations.

\section{Supplementary information}

Supplementary information accompanies this paper at https://doi.org/10. 1186/s40249-019-0603-z.

Additional file 1. Multilingual abstracts in the five official working languages of the United Nations.

Additional file 2. Algorithm for TB REACH active case finding through contact tracing, Nepal, 2018.

Additional file 3. Algorithm for TB REACH active case finding through TB camps and outpatient department of public hospitals, Nepal, 2018.

Additional file 4. TB REACH districts coverage and costing survey districts, Nepal, 2018.

\section{Abbreviations}

ACF: Active case finding; BNMT: Birat Nepal Medical Trust; CHWs: Community Health Workers; Cl: Confidence interval; DOTS: Directly observed treatment, short-course; MDR: Multi-drug-resistant; NPR: Nepalese rupees; NTP: National TB Programme; OPD: Outpatient department; OR: Odds ratio; PCF: Passive case finding; PIS: Patient information sheet; TB: Tuberculosis; WHO: World Health Organization

\section{Acknowledgements}

We thank all participants and households who consented to take part in this study. We also thank volunteer health workers and national TB program staff in Nepal.

\section{Authors' contributions}

SCG, KD, BR, MC, PRP, RD, SA, GB, DM, AR, BB, AT, GM, KS, AS, and NTSF were responsible for the initial study protocol and implementation. MC, NTSF, BS, $\mathrm{KL}$, JWL, JVR, KV, and TW contributed to the study design. BR, PRP, DM, SA, and GB collected the data. DW contributed to the statistical analysis. NTSF conducted the analysis. NTSF drafted the paper with input from all authors. MC edited the initial paper. All authors critically reviewed and commented on the paper. All authors read and approved the final paper for publication.
Funding

Stop TB Partnership/UNOPS - TB REACH project (grant number: 5-31):

European Union, Horizon 2020 - IMPACT TB project (grant number: 733174).

\section{Availability of data and materials}

The datasets generated and analyzed during the current study are not publicly available due to data protection law.

\section{Ethics approval and consent to participate}

Ethical approval was obtained from the Liverpool School of Tropical Medicine (N 17-019) and the Nepal Health Research Council (N 149 2017). Before interviews, patients received written and oral explanations of the study and signed an informed consent form.

\section{Consent for publication}

Not applicable.

\section{Competing interests}

The authors declare that they have no competing interests.

\section{Author details}

${ }^{1}$ Birat Nepal Medical Trust, Kathmandu, Nepal. ${ }^{2}$ Department of Clinical Sciences, Liverpool School of Tropical Medicine, Liverpool, UK. ${ }^{3} \mathrm{KNCV}$ Tuberculosis Foundation, The Hague, Netherlands. ${ }^{4}$ Department of Public Health Sciences, Karolinska Institutet, Stockholm, Sweden. ${ }^{5}$ Research School of Population Health, Australian National University, Canberra, Australia. ${ }^{6}$ University of St Andrews, St Andrews, UK. ${ }^{7}$ University of Liverpool, Liverpool, UK. ${ }^{8}$ Oxford University Clinical Research Unit, Kathmandu, Nepal. ${ }^{9}$ National

Tuberculosis Centre, Bhaktapur, Nepal. ${ }^{10}$ Nick Simons Institute, Lalitpur, Nepal.

${ }^{11}$ Institute for Health Technology Assessment, Porto Alegre, Brazil.

Received: 7 June 2019 Accepted: 23 October 2019

Published online: 03 December 2019

\section{References}

1. World Health Organization. The End TB Strategy. 2015. Available from: https://www.who.int/tb/post2015_strategy/en/

2. Richterman A, Steer-massaro J, Jarolimova J, Luong B. Cash interventions to improve clinical outcomes for pulmonary tuberculosis : systematic review and meta-analysis. Bull World Health Organ. 2018;96(7):471-83.

3. World Health Organization. Implementing the End TB Strategy: The Essentials. Geneva: World Health Organization; 2015. p. 1-130.

4. Stop TB Partnership. The Paradigm shift. Global plan to end TB. 2015. Available from: http://www.stoptb.org/global/plan/plan2/

5. The Britain Nepal Medical Trust, Oxford University Clinical Research Unit. Intensified case finding through contact tracing and initial default tracing to reach the targets of Nepal National TB Programme, National Strategic Plan 2010-2015 in nine districts. Nepal TB REACH Project, Wave 2. Programme Evaluation Report. 2014.

6. Fox GJ, Nhung NV, Sy DN, Hoa NLP, Anh LTN, Anh NT, et al. Householdcontact investigation for detection of tuberculosis in Vietnam. N Engl J Med. 2018;378(3):221-9.

7. Lung T, Marks GB, Nhung NV, Anh NT, Le N, Hoa P, et al. Household contact investigation for the detection of tuberculosis in Vietnam : economic evaluation of a cluster-randomised trial. Lancet Glob Health. 2019;7(3):e376-84.

8. Yassin MA, Datiko DG, Tulloch O, Markos P, Aschalew M, Shargie EB, et al. Innovative community-based approaches doubled tuberculosis case notification and improve treatment outcome in southern Ethiopia. PLoS One. 2013;8(5):1-8.

9. Lorent N, Choun K, Thai S, Kim T, Huy S, Pe R, et al. Community-based active tuberculosis case finding in poor urban settlements of Phnom Penh, Cambodia: a feasible and effective strategy. PLoS One. 2014;9(3):e92754.

10. Ayles H, Muyoyeta M, Du TE, Schaap A, Floyd S, Simwinga M, et al. Effect of household and community interventions on the burden of tuberculosis in southern Africa: the ZAMSTAR community-randomised trial. Lancet. 2013; 382(9899):1183-94.

11. World Health Organization. Eliminating the financial hardship of TB via Universal Health Coverage and other social protection measures. (Fact Sheet) [Internet]. Geneva, Switzerland; 2013 [cited 2019 Nov 9]. p. 1-2. Available from: https://www.who.int/tb/publications/UHC_SP_factsheet. pdf?ua=1. 
12. National Tuberculosis Centre, Departament of Health Services, National tuberculosis Centre. National Strategic Plan for Tuberculosis Prevention , Care and Control. 2016.

13. Government of Nepal, Ministry of Health and Population, Department of Health Services, National Tuberculosis Center. National Tuberculosis Program, Nepal. 2016.

14. World Health Organization. Nepal tuberculosis profile. 2018 [cited 2018 Nov 26]. Available from: https://extranet.who.int/sree/Reports?op= Replet\&name=\%2FWHO_HQ_Reports\%2FG2\%2FPROD\%2FEXT\%2 FTBCountryProfile\&ISO2=NP\&LAN=EN\&outtype $=h t m l$

15. Cousins S. Managing MDR tuberculosis in Nepal. Lancet. 2018;391(10132): 1760-1.

16. Mirzoev TN, Baral SC, Karki DK, Green AT, Newell JN. Community-based DOTS and family member DOTS for TB control in Nepal: costs and costeffectiveness. Cost Eff Resour Alloc. 2008:6:1-8.

17. de Cuevas RMA, Lawson L, Al-Sonboli N, Al-Aghbari N, Arbide I, Sherchand $\mathrm{JB}$, et al. Patients direct costs to undergo TB diagnosis. Infect Dis Poverty. 2016:5(1):1-9.

18. Ramsay A, Al-Agbhari N, Scherchand J, Al-Sonboli N, Almotawa A, Gammo $M$, et al. Direct patient costs associated with tuberculosis diagnosis in Yemen and Nepal. Int J Tuberc Lung Dis. 2010;14(2):165-70.

19. World Bank. Countries and economies: Nepal. 2018 [cited 2018 Nov 1]. Available from: https://databank.worldbank.org/data/views/reports/ reportwidget.aspx?Report_Name=CountryProfile\&ld=b450fd57\&tbar=y\&dd= $y \&$ inf $=n \& z m=n \&$ country $=N P L$

20. Goverment of Nepal, National Planning Commission, Central Bureau of Statistics. District Profile. 2018 [cited 2019 Mar 15]. Available from: https:// cbs.gov.np/district-profile/

21. Government of Nepal, Ministry of Health, Department of Health Services, National Tuberculosis Centre. Annual report 2073/74 (2017). Vol. 74. Thimi, Bhaktapur: National Tuberculosis Centre; 2017.

22. Tomeny EM, Mendoza VL, Marcelo DB, Barrameda AJD, Langley I, Abong JM, et al. A tuberculosis patient-cost survey considered in the context of patient-pathway modelling. Cavite: International Journal of Tuberculosis and Lung Diseases; 2019.

23. World Health Organization. In: WHO, editor. Tuberculosis patient costing surveys: a handbook. Geneva: WHO; 2017.

24. O'Donnell O, van Doorslaer $\mathrm{E}$, Wagstaff $\mathrm{A}$, Lindelow M. In: The World Bank, editor. Analyzing Health Equity Using Household Survey Data. Washington: The World Bank; 2008.

25. Government of Nepal, Ministry of Labor, Employment and Social Security. Minimum Wage Remuneration 2018 (2075). 2018 [cited 2018 Nov 20]. Available from: http://pioneerlaw.com/news/minimum-wageremuneration-2018-2075

26. OANDA. Historical exchange rates. 2016. 2018 [cited 2016 Aug 1]. Available from: https://www.oanda.com/fx-for-business/historical-rates

27. Faria R, Gomes M, Epstein D, White IR. A guide to handling missing data in cost-effectiveness analysis conducted within randomised controlled trials. Pharmacoeconomics. 2014;32(12):1157-70.

28. Rothman KJ, Greenland S. Introduction to Stratified Analysis. In: Rothman KJ, Lash SG TL, editors. Modern Epidemiology. 3rd ed. Philadelphia: Wolters Kluwer; 2012.

29. Morishita F, Yadav RP, Eang MT, Saint S, Nishikiori N. Mitigating financial burden of tuberculosis through active case finding targeting household and neighbourhood contacts in Cambodia. PLoS One. 2016;11(9):1-22.

30. Shewade HD, Gupta V, Satyanarayana S, Kharate A, Sahai KN, Murali L, et al. Active case finding among marginalised and vulnerable populations reduces catastrophic costs due to tuberculosis diagnosis. Glob Health Action. 2018;11(1):1494897.

31. Lorent N, Choun K, Malhotra S, Koeut P, Thai S, Khun KE, et al. Challenges from tuberculosis diagnosis to care in community-based active case finding among the urban poor in Cambodia: a mixed-methods study. PLoS One. 2015;10(7):1-15.

32. Tanimura $T$, Jaramillo $E$, Weil $D$, Raviglione $M$, Lönnroth $K$. Financial burden for tuberculosis patients in low- and middle-income countries: a systematic review. Eur Respir J. 2014;43(6):1763-75.

33. Wingfield T, Boccia D, Tovar M, Gavino A, Zevallos K, Montoya R, et al. Defining catastrophic costs and comparing their importance for adverse tuberculosis outcome with multi-drug resistance: a prospective cohort study, Peru. PLoS Med. 2014;11(7):e1001675.
34. Zhang D, Unschuld PU. China's barefoot doctor: past, present, and future. Lancet. 2008:372(9653):1865-7.

35. Khatri RB, Mishra SR, Khanal V. Female community health volunteers in community-based health programs of Nepal: future perspective. Front Public Heal. 2017;5(July):1-4.

36. Council for Technical Education and Vocational Training. Curriculum for Technical School Leaving Certificate in Community Medicine Assistant. Kathmandu; 2014.

37. Eang MT, Satha P, Yadav RP, Morishita F, Nishikiori N, Van-Maaren P, et al. Early detection of tuberculosis through community-based active case finding in Cambodia. BMC Public Health. 2012;12(1):1.

38. Nhung NV, Hoa NB, Anh NT, Anh LTN, Siroka A, Lönnroth K, et al. Measuring catastrophic costs due to tuberculosis in Viet Nam. Int J Tuberc Lung Dis. 2018;22(9):983-90.

39. Sweeney S, Vassall A, Foster N, Simms V, Ilboudo P, Kimaro G, et al. Methodological issues to consider when collecting data to estimate poverty impact in economic evaluations in low-income and middle-income countires. Health Econ. 2016;25(Suppl 1):42-52.

40. Carter DJ, Glaziou P, Lönnroth K, Siroka A, Floyd K, Weil D, et al. The impact of social protection and poverty elimination on global tuberculosis incidence: a statistical modelling analysis of sustainable development goal 1. Lancet Glob Heal. 2018:6(5):e514-22.

41. Oliosi JGN, Reis-Santos B, Locatelli RL, Sales CMM, da Silva Filho WG, da Silva $\mathrm{KC}$, et al. Effect of the Bolsa Familia Programme on the outcome of tuberculosis treatment: a prospective cohort study. Lancet Glob Heal. 2019; 7(2):e219-26.

42. Wingfield T, Tovar MA, Huff D, Boccia D, Montoya R, Ramos E, et al. The economic effects of supporting tuberculosis-affected households in Peru. Eur Respir J4. 2016;48(5):1396-410.
Ready to submit your research? Choose BMC and benefit from:
- fast, convenient online submission
- thorough peer review by experienced researchers in your field
- rapid publication on acceptance
- support for research data, including large and complex data types
- gold Open Access which fosters wider collaboration and increased citations
- maximum visibility for your research: over $100 \mathrm{M}$ website views per year
At BMC, research is always in progress.
Learn more biomedcentral.com/submissions 